УДК 316

10.17213/2075-2067-2021-1-94-102

\title{
СОЦИАЛЬНО-ЭКОНОМИЧЕСКОЕ НЕРАВЕНСТВО В ПРЕДСТАВЛЕНИИ МОЛОДЕЖИ РОСТОВСКОЙ ОБЛАСТИ
}

\author{
(C) 2021 г. А. И. Яковлева
}

\section{Южный федеральный университет, г. Ростов-на-Дону, Россия}

Цель исследования - изучение специфики сочииально-экономического неравенства в представлении студенческой молодежи Ростовской области.

Методология исследования. Работа базируется на результате авторского сочиологического исследования «Социально-экономическое неравенство в представлении студенческой молодежи Ростовской области», которое было проведено с использованием метода анкетного опроса, позволившего собрать эмпирическую информацию в ходе очного анкетирования респондентов (молодежи в возрасте от 14 до 30 лет) посредством регистрации их ответов на вопросы, заданные в соответствии с иелями и задачами исследования.

Результаты исследования. В представлениях молодежи Ростовской области социально-экономическое неравенство оказывает воздействие на жизнь молодого поколения. Большинство представителей молодежи области считает, что наличие неравного доступа $\kappa$ хорочим рабочим местам и образованию препятствует реализации жизненной стратегии и ограничивает возможности вертикальной мобильности в обществе. Социологическое исследование, посвященное анализу представлений студенческой молодежи Ростовской области относительно социально-экономического неравенства, позволило выявить влияние на него территориально-поселенческого фактора.

Перспективы дальнейшего использования результатов. В условиях нарастания угроз общественной безопасности остро сточт вопрос о реализачии мер по снижению уровня материального расслоения общества, преодолению бедности и повышению качества жизни населения России. В этой связи необходимо выявить основные направления деятельности, ориентированные на изменение институциональной среды российского общества, порождающей эти негативные социальные явления.

Ключевые слова: студенческая молодежь; Ростовская область; анкетирование; социально-экономическое неравенство; расслоение общества; бедность; территориальнопоселенческий фактор.

\section{SOCIO-ECONOMIC INEQUALITY IN THE REPRESENTATION OF THE YOUTH OF THE ROSTOV REGION}

\section{(C) 2021 A. I. Yakovleva}

\section{Southern Federal University, Rostov-on-Don, Russia}

The purpose of the study is to study the specifics of socio-economic inequality in the representation of the student youth of the Rostov region.

Research methodology. The work is based on the results of the author's sociological study "Socio-economic inequality in the representation of the student youth of the Rostov region", which 
was conducted using the method of a questionnaire survey, which allowed us to collect empirical information during a face-to-face survey of respondents (young people aged 14 to 30 years) by registering their answers to questions asked in accordance with the goals and objectives of the study.

The results of the study. In the views of the youth of the Rostov region, socio-economic inequality has an impact on the lives of the younger generation. The majority of young people in the region believe that the existence of unequal access to good jobs and education hinders the implementation of a life strategy and limits the opportunities for vertical mobility in society. A sociological study devoted to the analysis of the views of the student youth of the Rostov region regarding socio-economic inequality revealed the influence of the territorial settlement factor on it.

Prospects for further use of the results. In the context of increasing threats to public security, the issue of implementing measures to reduce the level of material stratification of society, overcome poverty and improve the quality of life of the Russian population is acute. In this regard, it is necessary to identify the main areas of activity aimed at changing the institutional environment of Russian society, which generates these negative social phenomena.

Key words: student youth; Rostov region; survey; socio-economic inequality; stratification of society; poverty; territorial and settlement factor.

Актуальность темы исследования обусловлена пониманием значимости проблемы глубокого социально-экономического неравенства, сложившегося в России в результате развития рыночных отношений и незавершенной модернизации социальных институтов общества. В настоящее время проблемы социально-экономического неравенства, имущественной поляризации общества, социальной политики государства воспринимаются крайне болезненно большинством населения страны.

Социальное расслоение российского общества, сложившееся в результате реформ, связано не только с глубоким социально-экономическим неравенством, но и с неравенством возможностей в самореализации, образовании, трудоустройстве, получении качественной медицинской помощи. Отсутствие перспектив восходящей мобильности ведет к нарастанию социальной напряженности, что создает ощущение нестабильности и небезопасности в обществе. В результате в общественном сознании граждан России сложилось представление о несправедливости нынешнего социального неравенства, существующего в стране.

Очевидно, что в нормально функционирующем обществе социально-экономическое неравенство выступает стимулом развития как человеческого капитала, так и экономики страны, поскольку в его основе лежит здоровая конкуренция. Однако, если речь идет о чрезмерном неравенстве, то в этом случае оно становится препятствием для мотивации человека на достижения, поскольку в таком обществе не работают каналы вертикальной социальной мобильности. Кроме того, избыточное социально-экономическое неравенство не стимулирует экономическое развитие социума.

По мнению специалистов, появление такого сильного расслоения за относительно небольшой период является достаточно редким историческим явлением. В связи с этим закономерно возникает вопрос о том, является ли данная ситуация результатом стихийных тенденций в современном российском обществе, или это вполне управляемый процесс, или он является следствием просчетов политического управления экономикой страны.

Представляется, что чрезмерная социально-экономическая дифференциация, сложившаяся в российском обществе, есть следствие деформации в системе распределения доходов в обществе, которая произошла в ходе экономических и политических реформ и привела к тому, что подавляющая часть общественного богатства страны сконцентрировалась в руках незначительной группы лиц, оказавшихся в этот период у власти, что 
способствовало появлению крупных монополий в различных отраслях экономики.

В результате в российском обществе произошло перераспределение доходов от рядовых граждан в пользу представителей властных структур, которое и привело к колоссальному социально-экономическому неравенству. В условиях сложившейся несправедливой системы распределения общественного богатства и отсутствия доверия общества к власти дальнейшее расслоение общества может привести к социальным конфликтам, способным дестабилизировать обстановку в стране и спровоцировать социальный хаос.

Сегодняшний уровень социально-экономического неравенства и рост бедности в стране являются серьезной угрозой экономической и политической стабильности государства. Ввиду этого проблема социально-экономического неравенства в российском обществе имеет как научную, так и социальную значимость. Это определяет необходимость исследования институциональной специфики социально-экономического неравенства и факторов его воспроизводства в современной России [1].

Степень изученности проблемы. В coциологическом знании проблема социально-экономического неравенства российского общества изучается такими авторами, как Л.А. Беляева [2], 3.Т. Голенкова [3], О.И. Шкаратан [4], Н.Е. Тихонова [5] и др. Все исследователи отмечают наличие в российском обществе глубокого социального раскола, сложившегося в результате структурных трансформаций постсоветской России. По мнению ученых, колоссальная поляризация российского общества обусловлена не только его транзитивным характером, но и неэффективностью системы государственного управления в решении социальных проблем населения. Исследованию социально-экономического неравенства в России в контексте проблемы бедности посвящены работы 3. П. Замараевой, К. А. Вороновой [6], В. Н. Иванова, А. Н. Суворова [7], В.В. Радаева [8], Р.М. Садыкова [9], Н.Е. Тихоновой [10] и др. Проблемы региональной бедности анализируются в исследованиях Е.И. Бегловой [11], М.К. Горшкова [12], Н.В.Проказиной, Т. М. Рожновой [13] и др.
Методология исследования. Работа базируется на результате авторского социологического исследования «Социально-экономическое неравенство в представлении студенческой молодежи Ростовской области». Социологическое исследование было проведено с использованием метода анкетного опроса, который позволил собрать эмпирическую информацию в ходе очного анкетирования респондентов (молодежи в возрасте от 14 до 30 лет) посредством регистрации их ответов на вопросы, заданные в соответствии с целями и задачами исследования. Объем выборочной совокупности исследования составляет 536 респондентов. Репрезентативность социологической информации обеспечивается использованием модели многоступенчатой районированной выборки с квотным отбором единиц наблюдения (респондентов) на последней ступени, представляющих молодое поколение в возрасте от 14 до 30 лет Ростовской области в разбивке по типу поселения, возрасту, полу, материальной обеспеченности.

Результаты исследования. Социологические замеры социально-экономического неравенства в российском обществе свидетельствуют о том, что оно достигло критического максимума. Снижение уровня жизни большинства населения России обусловлено кризисным состоянием экономики страны, которое повлекло за собой: 1) рост цен и девальвацию рубля; 2) рост безработицы в результате закрытия ряда предприятий; 3) появление задолженности по заработной плате в некоторых секторах экономики; 4) сокращение расходов на граждан из бюджета.

В результате в социальной сфере произошло увеличение числа фактических бедных в России, падение уровня жизни российских граждан, ухудшение жизни наиболее уязвимых категорий граждан - пенсионеров, инвалидов, малообеспеченных семей, молодежи. Все эти негативные тенденции привели к обнищанию населения России.

Анализ бедности в России позволил выделить основные группы населения, попадающие в российском обществе в категорию бедных: а) «работающая бедность», основной причиной появления этой группы является низкий уровень оплаты труда (в первую очередь, это касается работников бюджетной 
сферы); б) семьи с детьми, инвалидами (причиной бедности этой категории населения выступает неэффективная социальная политика государства); в) пенсионеры, основными причинами бедности которых является низкий размер пенсий, а также ограниченный доступ к социальным и медицинским услугам (льготам в том числе); г) молодежь, которая является социально незащищенной группой, сталкивающейся с проблемами получения образования, поиска работы, наличием безработицы, низких доходов, отсутствия своего жилья. Причем «бедность» молодежи не измеряется прожиточным минимумом, в первую очередь, она выражается в отсутствии возможностей личностной и профессиональной самореализации, осуществления жизненных планов.

Проведенное нами социологическое исследование на тему «Социально-экономическое неравенство в представлении студенческой молодежи Ростовской области» свидетельствует о том, что проблема неравенства волнует молодежь: $63 \%$ относится негативно к неравенству, сложившемуся в обществе, причем молодежь Ростовской области, в первую очередь, волнует неравенство в доступе к хорошим рабочим местам (78\%), затем в сфере доходов (53\%) и доступности медицинской помощи $(53 \%)$, доступности образования $(28 \%)$ и возможностях проведения досуга (26\%) (рис. 1). При оценке влияния социально-экономического неравенства на свою жизнь мнение респондентов разде- лилось: $30 \%$ считают, что оказывает существенное влияние; $37 \%$ ответили, что влияет; $30 \%$ полагает, что влияет незначительно. Эти показатели дают основание говорить о том, что в представлениях молодежи Ростовской области социально-экономическое неравенство оказывает воздействие на жизнь молодого поколения. Большинство представителей молодежи области считают, что наличие неравного доступа к хорошим рабочим местам и образованию препятствует реализации жизненной стратегии и ограничивает возможности вертикальной мобильности в обществе.

Социологическое исследование, посвященное анализу представлений студенческой молодежи Ростовской области относительно социально-экономического неравенства, позволило выявить влияние на него территориально-поселенческого фактора. Оценки молодежи, принадлежащей к разным типам поселений (город и село), своего уровня материальной обеспеченности свидетельствуют о том, что у сельской молодежи этот уровень ниже (табл. 1).

Данные таблицы демонстрируют, что уровень жизни молодежи тесно связан с проживанием на определенной поселенческой территории. Для определения зависимости уровня жизни от места жительства социологи используют термин «поселенческая асимметрия в доходах» [14], который отражает различие в уровнях доходов жителей сельской местности по сравнению с жителями города. Причем эта асимметрия имеет объек-

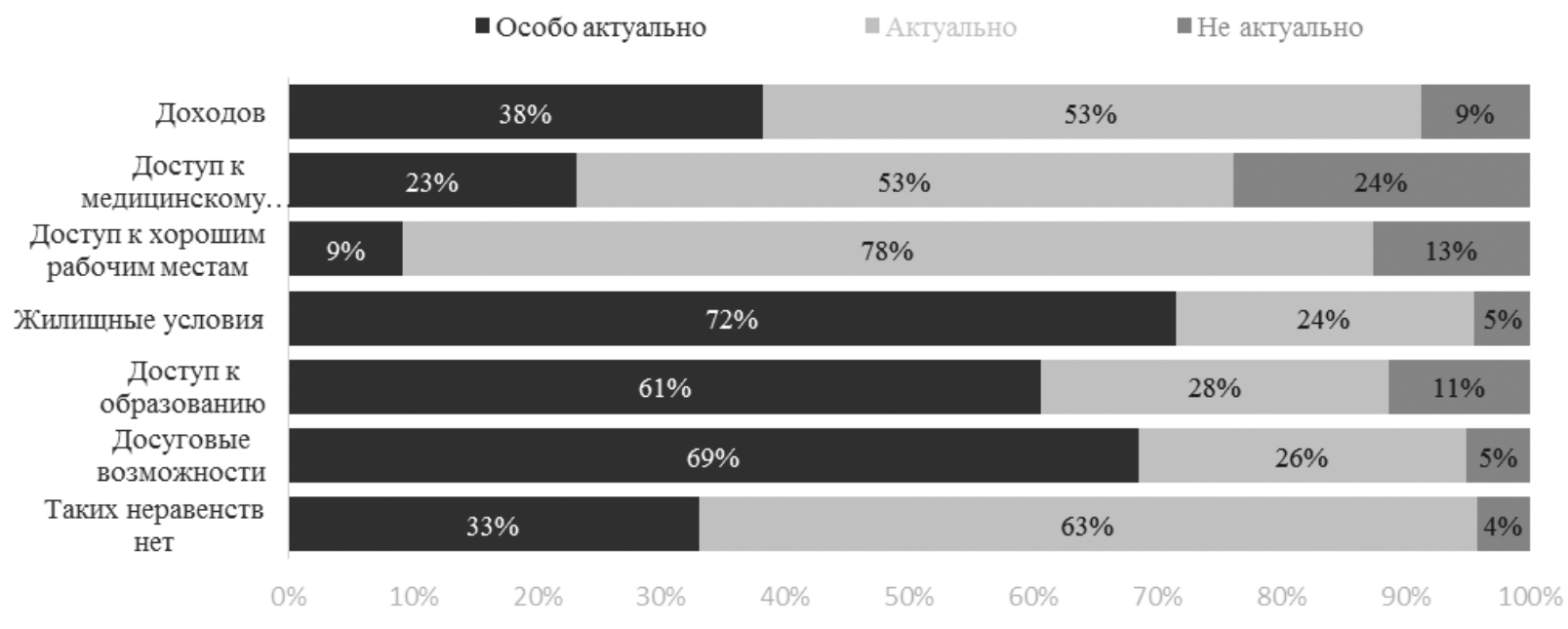

Рис. 1. Социально-экономическое неравенство в различных аспектах жизни молодежи Ростовской области, в \% от количества опрошенных 
Таблица 1

\section{Оценка молодежью разных типов поселений и уровня материальной обеспеченности различных аспектов своей жизни ${ }^{1}$}

\begin{tabular}{|c|c|c|c|}
\hline \multirow[t]{2}{*}{ Материальная дифференциация молодежи } & \multicolumn{2}{|c|}{$\begin{array}{c}\text { Территориальная } \\
\text { дифференциация } \\
\text { молодежи }\end{array}$} & \multirow[t]{2}{*}{$\begin{array}{l}\text { Молодежь } \\
\text { в целом }\end{array}$} \\
\hline & $\begin{array}{l}\text { Городская } \\
\text { молодежь }\end{array}$ & $\begin{array}{c}\text { Сельская } \\
\text { молодежь }\end{array}$ & \\
\hline \multicolumn{4}{|c|}{ Оченка материальной обеспеченности } \\
\hline $\begin{array}{l}\text { Низкий уровень доходов (денег хватает только на самое } \\
\text { необходимое, питание, оплату коммунальных платежей) }\end{array}$ & 2,6 & 2,1 & 2,4 \\
\hline $\begin{array}{l}\text { Удовлетворительный уровень доходов (живем более- } \\
\text { менее прилично, но покупка большинства товаров вы- } \\
\text { зывает затруднения) }\end{array}$ & 2,9 & 2,5 & 2,7 \\
\hline $\begin{array}{l}\text { Средний уровень доходов (средств хватает на все, кроме } \\
\text { таких крупных приобретений, как, например, квартира) }\end{array}$ & 3,3 & 2,8 & 3,1 \\
\hline $\begin{array}{l}\text { Высокий уровень доходов (материальных затруднений } \\
\text { не испытываем, при необходимости могли бы приоб- } \\
\text { рести квартиру) }\end{array}$ & 4 & 4,5 & 4,2 \\
\hline \multicolumn{4}{|l|}{ Оценка своего питания } \\
\hline Низкий уровень доходов & 3,5 & 3,3 & 3,4 \\
\hline Удовлетворительный уровень доходов & 3,8 & 3,5 & 3,65 \\
\hline Средний уровень доходов & 4,3 & 4 & 4,15 \\
\hline Высокий уровень доходов & 5 & 4,5 & 4,75 \\
\hline \multicolumn{4}{|l|}{ Оценка жилищных условий } \\
\hline Низкий уровень доходов & 2,8 & 2,1 & 2,45 \\
\hline Удовлетворительный уровень доходов & 3,1 & 2,8 & 2,95 \\
\hline Средний уровень доходов & 4,5 & 4 & 4,25 \\
\hline Высокий уровень доходов & 4,8 & 4,3 & 4,55 \\
\hline \multicolumn{4}{|c|}{ Оченка возможности приобретения одежды } \\
\hline Низкий уровень доходов & 2 & 1,8 & 1,9 \\
\hline Удовлетворительный уровень доходов & 2,5 & 2 & 2,25 \\
\hline Средний уровень доходов & 3 & 2,3 & 2,65 \\
\hline Высокий уровень доходов & 4 & 3,1 & 3,55 \\
\hline \multicolumn{4}{|l|}{ Оценка возможностей проведения досуга } \\
\hline Низкий уровень доходов & 2 & 2,1 & 2,05 \\
\hline Удовлетворительный уровень доходов & 2,3 & 2,3 & 2,3 \\
\hline Средний уровень доходов & 3,1 & 2,5 & 2,8 \\
\hline
\end{tabular}

1 Для оценки различных аспектов жизни респондентов нами был рассчитан средневзвешенный коэффициент. Интерпретация значения средневзвешенного коэффициента: если его значение менее «3», это свидетельствует о низком уровне оценки респондентами данной сферы жизни, если значение выше «3» - свидетельствует о высоком уровне оценки респондентами данной сферы жизни. 
Окончание таблицы 1

\begin{tabular}{|l|c|c|c|}
\hline Высокий уровень доходов & 4,1 & 4,5 & 4,3 \\
\hline \multicolumn{3}{|c|}{ Оценка возможностей реализацчии в профессии } \\
\hline Низкий уровень доходов & 2 & 2 & 2 \\
\hline Удовлетворительный уровень доходов & 2,5 & 2,3 & 2,4 \\
\hline Средний уровень доходов & 3,3 & 3,4 & 3,35 \\
\hline Высокий уровень доходов & 3,8 & 4 & 3,9 \\
\hline
\end{tabular}

Оиенка возможностей получения образования

\begin{tabular}{|l|c|c|c|}
\hline Низкий уровень доходов & 2,8 & 2,5 & 2,65 \\
\hline Удовлетворительный уровень доходов & 3,1 & 3 & 3,05 \\
\hline Средний уровень доходов & 4,1 & 3,8 & 3,95 \\
\hline Высокий уровень доходов & 4,8 & 4,5 & 4,65
\end{tabular}

\begin{tabular}{|l|c|c|c|}
\hline \multicolumn{3}{|c|}{ Оченка территории проживания } \\
\hline Низкий уровень доходов & 3,8 & 3,6 & 3,7 \\
\hline Удовлетворительный уровень доходов & 4 & 4 & 4 \\
\hline Средний уровень доходов & 4,5 & 4,6 & 4,55 \\
\hline Высокий уровень доходов & 4,7 & 4,6 & 4,65 \\
\hline
\end{tabular}

\begin{tabular}{|l|c|c|c|}
\hline \multicolumn{4}{|c|}{ Оценка своего статуса в обществе } \\
\hline Низкий уровень доходов & 3,1 & 2,5 & 2,8 \\
\hline Удовлетворительный уровень доходов & 3,8 & 3 & 3,4 \\
\hline Средний уровень доходов & 4,5 & 4 & 4,25 \\
\hline Высокий уровень доходов & 4,8 & 4,6 & 4,7 \\
\hline
\end{tabular}

Оиенка личной безопасности

\begin{tabular}{|l|c|c|c|}
\hline Низкий уровень доходов & 2 & 3,1 & 2,55 \\
\hline Удовлетворительный уровень доходов & 2,5 & 3,3 & 2,9 \\
\hline Средний уровень доходов & 4 & 4 & 4 \\
\hline Высокий уровень доходов & 4,9 & 5 & 4,95 \\
\hline \multicolumn{4}{|c|}{ Оценка жизни в цุелом } \\
\hline Низкий уровень доходов & 2,8 & 2,3 & 2,55 \\
\hline Удовлетворительный уровень доходов & 3,5 & 3,5 & 3,5 \\
\hline Средний уровень доходов & 4 & 4 & 4 \\
\hline Высокий уровень доходов & 4,5 & 4,9 & 4,65 \\
\hline
\end{tabular}

тивные основания: отсутствие рабочих мест, отраслевые различия в оплате труда, преобладание сельскохозяйственного вида производственной деятельности, уровень оплаты которой значительно ниже, чем в других отраслях экономики.

Анализируя характер и показатели общероссийской и региональной бедности, можно сделать вывод о том, что основные их причины лежат в организации экономической сферы общества и деятельности политических институтов. К ним можно отнести следующие:

a) низкотехнологичный характер производства, который ориентирован на низкооплачиваемые рабочие места; 
б) низкий уровень оплаты труда квалифицированных кадров;

в) специфика российского трудового законодательства, не устанавливающего нормы соответствия заработной платы работников и руководителей предприятий;

г) несформированность институтов гражданского общества, в частности, профсоюзных организаций, отстаивающих права работающего населения.

Заключение. Социологические замеры фиксируют, что сложившееся в результате реформ социальное расслоение и разобщение связано с неравенством возможностей в самореализации, образовании, трудоустройстве, получении качественной медицинской помощи. Отсутствие перспектив восходящей мобильности ведет к нарастанию социальной напряженности, что создает ощущение нестабильности и небезопасности в обществе.

В условиях нарастания угроз общественной безопасности остро стоит вопрос о реализации мер по снижению уровня материального расслоения общества, преодолению бедности и повышению качества жизни населения России. В этой связи необходимо выявить основные направления деятельности, ориентированные на изменение институциональной среды российского общества, порождающей эти негативные социальные явления.

\section{Литература}

1. Яковлева А. И. Социально-экономическое неравенство в российском обществе: социокультурные особенности и современные тенденции: монография / Отв. ред. Ю.Г. Волков. - Ростов-на-Дону: Фонд науки и образования, 2020. - $150 \mathrm{c}$.

2. Беляева Л. А. Россия и Европа: структура населения и социальное неравенство// Мониторинг общественного мнения. - 2010. №3 (97).

3. Голенкова 3.T. Динамика социоструктурной трансформации в России // Социологические исследования. - 1998. - №10.

4. Шкаратан О.И. Социально-экономическое неравенство в современном мире и становление новых форм социального расслоения в России // Мир России. - 2018. T. 27. 一 №2.
5. Тихонова Н.Е. Социальная стратификация в современной России: опыт эмпирического анализа. - М.: ИС РАН, 2007.

6. Замараева 3.П., Воронова К.А. Феномен бедности в социологии с позиции факторного и ресурсного анализа // Вестник Пермского университета. Философия. Психология. Социология. - 2018. - Вып. 1.

7. Иванов В.Н., Суворов А.Н. Неравенство и бедность населения: опыт решения проблем в России и за рубежом // Проблемы прогнозирования. - 2006. - №3.

8. Радаев В. В. Работающие бедные: велик ли запас прочности // Социологические исследования. - 2000. - №8.

9. Садыкков Р.М. Проблемы бедности в России: особенности и тенденции [Электронный ресурс] // Научно-методический электронный журнал «Концепт». - 2018. - №7 (июль). - Режим доступа: http://e-koncept. ru/2018/184030.htm.

10. Тихонова Н.Е. Структурные предпосылки и основные типы российской бедности// Общественные науки и современность. - 2014. - №2.

11. Беглова Е.И. Бедность в регионах России // Стратегия устойчивого развития регионов России. - 2011. - №5.

12. Столицы и регионы в современной России: мифы и реальность пятнадцать лет спустя / Отв. ред. М.К. Горшков, Н.Е. Тихонова. - М.: Весь Мир, 2018.

13. Проказина Н.В., Рожнова Т.М. Бедность в региональном измерении: причины и факторы возникновения // Научный результат. Социология и управление. - 2018. T. 4. - №4.

14. Лейман Т. И. Ассиметрия доходов населения как форма неравенства в трансформационной экономике России: дисс. канд. экон. наук. - СПб., 2010.

\section{References}

1. Jakovleva A.I. Social'no-jekonomicheskoe neravenstvo $\mathrm{v}$ rossijskom obshhestve: sociokul'turnye osobennosti i sovremennye tendencii: monografija [Socio-economic inequality in Russian society: socio-cultural features and modern trends: monograph] / Otv. red. Ju. G. Volkov [In Yu. G. Volkov (eds.)]. — Rostov-on-Don: Fond nauki i obrazovanija, 2020. - $150 \mathrm{p}$. 
2. Beljaeva L.A. Rossija i Evropa: struktura naselenija i social'noe neravenstvo [Russia and Europe: the structure of the population and social inequality] // Monitoring obshhestvennogo mnenija [Public opinion monitoring]. 2010. 一 №3 (97).

3. Golenkova Z.T. Dinamika sociostrukturnoj transformacii $\mathrm{v}$ Rossii [Dynamics of sociostructural transformation in Russia] // Sociologicheskie issledovanija [Sociological research]. — 1998. — №10.

4. Shkaratan O.I. Social'no-jekonomicheskoe neravenstvo $\mathrm{v}$ sovremennom mire $\mathrm{i}$ stanovlenie novyh form social'nogo rassloenija v Rossii [Socio-economic inequality in the modern world and the formation of new forms of social stratification in Russia] // Mir Rossii [The world of Russia]. — 2018. - Vol. 27. — №2.

5. Tihonova N.E. Social'naja stratifikacija v sovremennoj Rossii: opyt jempiricheskogo analiza [Social stratification in modern Russia: experience of empirical analysis]. - Moscow: IS RAN, 2007.

6. Zamaraeva Z.P., Voronova K.A. Fenomen bednosti $\mathrm{v}$ sociologii s pozicii faktornogo $\mathrm{i}$ resursnogo analiza [The phenomenon of poverty in sociology from the perspective of factual and resource analysis] // Vestnik Permskogo universiteta. Filosofija. Psihologija. Sociologija [Bulletin of the Perm University. Philosophy. Psychology. Sociology]. - 2018. - Issue 1.

7. Ivanov V.N., Suvorov A.N. Neravenstvo $\mathrm{i}$ bednost' naselenija: opyt reshenija problem $\mathrm{v}$ Rossii i za rubezhom [Inequality and poverty of the population: experience of solving problems in Russia and abroad] // Problemy prognozirovanija [Problems of forecasting]. - 2006. №3.

8. Radaev V.V. Rabotajushhie bednye: velik li zapas prochnosti [Working poor: is the margin of safety large] // Sociologicheskie issledovanija [Sociological research]. — 2000. — №8.

9. Sadykov R. M. Problemy bednosti v Rossii: osobennosti i tendencii [Problems of poverty in Russia: features and trends] [Jelektronnyj resurs] // Nauchno-metodicheskij jelektronnyj zhurnal «Koncept»[Scientific and methodological electronic journal «Concept»]. 2018. — №7 (July). — URL: http://e-koncept. $\mathrm{ru} / 2018 / 184030 . \mathrm{htm}$.

10. Tihonova N.E. Strukturnye predposylki i osnovnye tipy rossijskoj bednosti [Structural prerequisites and basic types of the Russian poor] // Obshhestvennye nauki i sovremennost' [Social Sciences and Modernity]. — 2014. — №2.

11. Beglova E.I. Bednost' v regionah Rossii [Poverty in the regions of Russia] // Strategija ustojchivogo razvitija regionov Rossii [Strategy for sustainable development of Russian regions]. - 2011. — №5.

12. Stolicy i regiony v sovremennoj Rossii: mify i real'nost' pjatnadcat' let spustja [Capitals and regions in modern Russia: myths and reality fifteen years later] / In M.K. Gorshkov, N.E. Tihonova (eds.). - Moscow: Ves' Mir, 2018.

13. Prokazina N.V., Rozhnova T.M. Bednost' $v$ regional'nom izmerenii: prichiny i faktory vozniknovenija [Poverty in the regional dimension: causes and factors of occurrence] // Nauchnyj rezul'tat. Sociologija i upravlenie [Scientific result. Sociology and Management]. — 2018. Vol. 4. - №4.

14. Lejman T.I. Assimetrija dohodov naselenija kak forma neravenstva $\mathrm{v}$ transformacionnoj jekonomike Rossii: diss. kand. jekon. nauk [Population income asymmetry as a form of inequality in the transformational economy of Russia: Ph. D. Sci. (Economic) diss.]. — Saint Petersburg, 2010. 


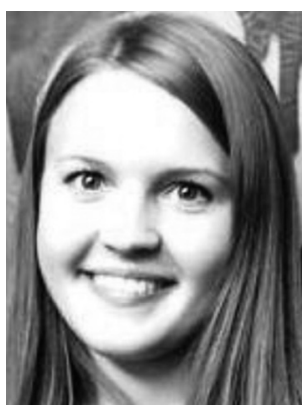

Яковлева Анна Игоревна - соискатель Южного федерального университета.

Yakovleva Anna Igorevna - Candidate of the Southern Federal University.

344006, г. Ростов-на-Дону, ул. Большая Садовая, 105/42 105/42 Bolshaya Sadovaya st., Rostov-on-Don, 344006, Russia E-mail: galia201292@gmail.com 